\title{
A IMPORTÂNCIA DA CONTAÇÃO DE HISTÓRIAS NA EDUCAÇÃO INFANTIL
}

\author{
Adriana Fátima Arruda da Costa ${ }^{\mathrm{I}}$ \\ Andréia Aparecida de Sales ${ }^{2}$ \\ Benedita Paulina da Silva ${ }^{3}$ \\ Renata Regina de Araújo do Monte ${ }^{4}$ \\ Jucinete Bondespacho Arruda da Mata
}

RESUMO: Este artigo tem como objetivo analisar a importância da contação de histórias na educação infantil, enfatizar a contribuição para a sociedade e a cognição e fortalecer as intenções educacionais e de aprendizagem das crianças. Para a realização desta pesquisa, foram realizadas leituras e análises do texto, com pesquisa bibliográfica, e também com base na experiência da educação infantil. No uso da contação de história em sala de aula, todos os participantes da educação compartilham suas emoções, sejam os alunos inspirados a imaginar e criar, ou os professores terão uma aula mais agradável e produtiva. Outro ponto que compartilham dessa emoção é o desenvolvimento da comunicação, devido ao estímulo da linguagem falada, isso faz com que as crianças conversem com seus colegas e professores.

Palavras-chave: Educação Infantil. Contação de História. Trabalho Docente.

ABSTRACT: This article aims to analyze the importance of storytelling in early childhood education, emphasize the contribution to society and cognition, and strengthen children's educational and learning intentions. To carry out this research, readings and analysis of the text were carried out, with bibliographical research, and also based on the experience of early childhood education. In the use of storytelling in the classroom, all education participants share their emotions, whether students are inspired to imagine and create, or teachers will have a more enjoyable and productive lesson. Another point they share in this emotion is the development of communication, due to the stimulus of spoken language, this makes children talk to their peers and teachers.

Keywords: Early Childhood Education. Storytelling. Teaching work.

\footnotetext{
${ }^{1}$ Graduada em Pedagogia pela Universidade Pitágoras Unopar, Especialista em Educação Infantil e as Séries Iniciais pela Faculdades Integradas de Ariquemes - FIAR.

${ }^{2}$ Graduada em Pedagogia pela Universidade Luterana do Brasil - ULBRA, Especialista Educação Infantil e Especial pela Faculdade das Águas Emendadas - FAE.

${ }^{3}$ Graduada em Letras pelo Centro Universitário de Várzea Grande - UNIVAG, Graduada em Pedagogia pela Faculdade de Ciências de Wenceslau Braz - FACIBRA, Especialista em Educação Infantil e Especial pela Universidade Cândido Mendes - UCAM.

${ }^{4}$ Graduada em Pedagogia pela Universidade Federal de Mato Grosso - UFMT, Especialista em Alfabetização Matemática pela Faculdade São Bráz.

${ }^{5}$ Graduada em Pedagogia pela Universidade Federal de Mato Grosso - UFMT.
} 


\section{INTRODUÇÃO}

A contação de histórias existe no universo escolar desde muito tempo, embora diversos professores ainda não reconhecem o quanto às histórias podem ajudá-los em sua prática educativa. $\mathrm{O}$ ato de contar história é uma arte milenar que está presente em várias culturas. Elas são organizadas em conformidade com o repertório de mitos que a sociedade determina, ou seja, produz. Ao contar história para crianças, abre-se uma oportunidade para que estes mitos, tão importantes para construção de sua identidade social, possam ser apresentadas a elas.

A contação de história parte do princípio, da necessidade de comunicação, da vontade de estar junto a outras pessoas, partilhando o sentimento que se move do coração e sai pelo olhar, da historia oralizada pela palavra. Contar história hoje denota salvar o mundo imaginário (SISTO, 200I).

A contação de história é uma grande ferramenta que desperta o senso crítico e reflexivo não somente das crianças, mas de todos os ouvintes, podendo um mesmo texto ser interpretado do vários modos. É possível dizer que a contação de histórias em sala de aula é

uma diverção, estimula a imaginação dos alunos e promove o despertar e o interesse pela leitura, através da narração de uma história é um exercício de renovação de vida, um ponto de partida para ensinar os conteúdos programáticos para entender o que ocorre com os alunos no campo pessoal.

De acordo com Jolibert (1994, p. 14) lendo nos tornamos leitor e não aprendendo primeiro para ler depois: não é autentico tentar uma diferença, nem no tempo, nem na natureza da atividade, entre "aprender a ler e ler”. Ler é entender o sentido das coisas, por isso entender o outro. Quem lê se transforma através do sentido que as palavras produzem.

O objetivo deste artigo é analisar a importância da contação de história na educação infantil, com ênfase na contribuição para os aspectos social, cognitivo, assim como também reforçando as intenções educativas e de aprendizagem da criança e identificando as práticas empregadas no trabalho docente para a contação de histórias na educação infantil, uma vez que a mesma se tornou tão presente no mundo cotidiano das crianças em diferentes partes do mundo.

O mesmo foi desenvolvido através de pesquisa bibliográfica tendo como base diversos autores que tratam deste tema tais como: Faria (2010), Fernandes (2003), Jolibert 
(1994), Sisto (2001), Amarilha (1997), Cavalcanti (2002), bem como teve pautado na experiência prática na Educação Infantil, que favoreceu a presente análise mediante as práticas de contação de histórias com crianças.

\section{DESENVOLVIMENTO}

2.I A contação de história na educação infantil

Partindo da afirmativa de que empregamos a contação de histórias para promover estímulos à leitura, podemos então dizer que sonhar imaginar, sentir, são contribuições essenciais nesse processo. A contação de histórias possibilita nas crianças o desenvolvimento de operações mentais que auxiliam na construção dos significados das palavras ouvidas, de forma que incorporadas ao contexto da história, possam, além de enriquecer o seu vocabulário, auxiliar no desenvolvimento da leitura e da escrita.

De acordo com Faria (2010), existem três níveis de leitura. Num primeiro momento é o tato, o prazer de tocar o livro com o papel agradável, com ilustrações, figuras e planejamento gráfico caprichado. No segundo momento ocorre o emocional é aquele em que a fantasia e a liberdade das emoções mostram o que ele faz e o que provoca em nos, e terceiro momento o nível racional que está ligado, ao plano intelectual da leitura.

As contribuições de uma contação de histórias são distinguidas, e são importantes no auxílio da formação das crianças, na compreensão e absorção dos significados, assim como o desenvolvimento das práticas leitoras. As crianças que escutam as histórias incorporam uma atitude analítica exemplificada pelo orador, através de seus comentários e problematizações durante a contação de histórias, favorecendo o desenvolvimento do senso crítico.

[...] o texto literário é polissêmico, pois sua leitura provoca no leitor reações diversas, que vão do prazer emocional ao intelectual. Além de simplesmente fornecer informação sobre diferentes temas históricos, sociais, existenciais e éticos, por exemplo -, eles também oferecem vários outros tipos de satisfação ao leitor: adquirir conhecimentos variados, viver situações existenciais, entrar em contato como novas idéias etc (FARIA, 2010, p. I2).

Sobretudo por essas razões que o texto literário, em especial a contação de história se caracteriza como um instrumento importante para que o professor possa criar momentos 
reais de atividades em sala de aula, resultando na motivação e necessidade de ler nas crianças, desde muito pequenas.

A contação de história atua na formação da criança em diversas áreas, contribui no desenvolvimento intelectual despertando assim o interesse pela leitura e instigando a imaginação através da construção de imagens no mundo quer seja da realidade e da ficção, agindo também no desenvolvimento comunicativo assim, que a sua provocação da oralidade leva o aluno a dialogar com seus colegas, desenvolvendo, além disso, a interação sóciocultural da criança ao proporcionar essas interações entre os alunos e criação de laços sociais e formação de gosto pela literatura e artes.

Um trabalho minucioso com crianças, apontando ou levando-as a descobrir esses elementos técnicos que fazem progredir a ação ou que explicam espaço, tempo, características das personagens etc. aprofundará a leitura da imagem e da narrativa e estará, ao mesmo tempo, desenvolvendo a capacidade de observação, análise, comparação, classificação, levantamento de hipóteses, síntese e raciocínio (FARIA, 2010, p. 59).

Entre as particularidades da literatura infantil, Faria (2010) sinaliza para o fato da literatura infantil ser um gênero literário destinado em especial às crianças e conta hoje com vários recursos, como diferentes suportes de texto, ilustrações cada vez mais ricas, grande variedade de histórias e temas, entre outros fatores, que podem auxiliar o professor na complexa tarefa de formar crianças leitoras.

Partindo da nossa experiência na Educação Infantil podemos afirmar que o professor pode abordar vários temas, além de colocar o aluno em contato com diferentes tipos de textos, não apenas narrativos, uma vez que hoje o universo da literatura infantil possui uma diversidade bem ampla de obras e diferentes recursos gráficos e materiais capazes de chamar e prender a atenção do leitor, ou seja, da criança.

\subsection{A CONTAÇÃO DE HISTÓRIA E A PRÁTICA DOCENTE}

Sabemos que nem sempre a contação de história é uma prática muito estimulada e valorizada, partindo do próprio professor esta falta de interesse. Muitos afirmam que é uma atividade sem significados que leva as crianças a crescerem com essa desvalorização dos contos. Os professores podem e devem valorizar a contação de histórias, mostrando que isso é muito importante no desenvolvimento infantil. 
Amarilha (1997) afirma a importância da literatura na formação cognitiva, lingüística, comunicativa e psicológica da criança. Existe a necessidade de implementar práticas pedagógicas prazerosas e regulares, como contar e ler textos dos contos de fadas, para garantir uma relação escolar bem- sucedida, visto que a leitura é ferramenta instrumental na cultura brasileira.

É de suma importância que, antes de uma revolução na prática, exista uma revisão no acervo teórico que nos embasa como também o nosso próprio entendimento de leitura e de mundo, proporcionando assim um espaço para o conhecimento de como a literatura infantil pode ser permite no mundo escolar dentro de uma perspectiva lúdica e prazerosa.

Antes de qualquer contação de história é necessário que prepare uma sessão para entrar no mundo da imaginação para que o leitor-ouvinte sinta-se convidado a conhecer segredos e revelações, momento de inteira confiança. Uma estratégia pedagógica que pode permitir de modo significativo a pratica docente na educação infantil.

[...] contar história é algo que caminha do simples para o complexo e que implica estabelecer vínculos e confiança com os ouvintes. Contar história é confirmar um compromisso que vem de longe e por isso, atividades relacionadas às contações de história devem ser desenvolvidas com muito critério (CAVALCANTI, 2002, p. 83).

No momento em que a humanidade se percebe na construção de tecnologias na utilização de textos escritos através de pinturas, dramatização colagens, sonoridade, ou seja, imagem que se comunica de forma múltipla, fica mais difícil chamar a atenção da criança para a contação de histórias onde cada vez mais se faz necessário essa prática, pois o momento de uma história estimula uma expectativa de mistério e sedução e nesse período se concretiza toda felicidade da criança, ela entra no mundo da ficção para poder lidar com o real e o imaginário.

Vivemos atualmente sujeitos e uma avalanche de apelos aos diversos sentidos. Luz, cor, movimento, sons e ação atraem a atenção do leitor que passivamente se entregar ao mundo "encantado" da televisão. Assim, não é fácil conquistar a criança e o jovem para a leitura de livros, embora todos saibam que a literatura pode provocar e despertar uma gama de sentidos, símbolos (CAVALCANTI, 2002, p. 84). 
Os docentes conhecem o que um conto de uma história desempenha nas crianças. Quando não consegue prender a atenção, eles oferecem uma história e imediatamente o estudo em sala de aula se refaz; defendendo a idéia de que tal ocasião proporciona interação entre os alunos e o professor, despertando o interesse pela leitura, estimulando assim a formação de bons leitores. O profissional da educação, quando passa a ser contador de história, faz do exercício de contar ao seu modo de falar, deixa de ser pessoa simplesmente e entre em um mundo que somente a criança compreende.

Amarilha (1997) diz que existem pesquisas realizadas com crianças de até oito anos de idade que evidenciam a eficiência do trabalho com os contos infantis no sucesso das crianças em sua auto-estima, sua identidade cultural, sua independência e sua capacidade de lidar com o mundo a sua volta.

A linguagem e os enredos literários proporcionam à criança possibilidade de sucesso em duas dimensões. Uma, que é a subjetiva, a criança pode viver no livro aquilo que mais lhe atrai, sem receio de ser assistida, principalmente, por um adulto e pode lidar com seus problemas em tempos e espaços que são todos seus; por outro lado, mantém-se relacionada ao real, ela tem consciência de que não deixa de ser leitor. Essa duplicidade de atividade intelectual familiariza a criança com o simbólico e com suas possibilidades intelectuais dando-lhe, portanto, auto-estima e identidade psicológica e social (AMARILHA, 1997, p. 55).

O contato com a literatura infantil especialmente através da contação de história as crianças se familiarizam com a forma lingüística mais elaborada, pois, essa relação com a linguagem deve ser uma meta pedagógica maior principalmente na educação infantil. Durante a realização de nossa prática na Educação Infantil temos acompanhados de perto cada ação e reação das crianças no momento da contação de histórias, estimulando o senso critico em relação aos fatos das narrativas, no início as crianças se mostram um tanto tímidas, mas durante a realização da oralidade das narrativas percebemos as expectativas das crianças em querer ouvilas e ficavam deslumbradas com todos os gestos e entonação de voz.

A atividade com o "baú de histórias", os alunos se sentam no chão em círculo e cada um deles imaginam o que teriam achado dentro de um baú imaginário e verbalizam o que veem e passavam o baú para o próximo aluno e assim, conseqüentemente, até terminar o círculo. 
A rodinha a prática da linguagem oral, onde as crianças podem brincar com as palavras com muita facilidade, imitando as vozes, passam a despertar emoções como se estivessem vivendo o que lhe é narrado, os sentimentos apresentados permitem que a criança, através da imaginação, exercitem a capacidade de resolução de situações que vive em seu cotidiano.

A contação de história é utilizada como auxílio para que a aprendizagem se torne mais interessante, já que a oralidade é bastante enfatizada e o imaginário estimulado. Contudo, compreende-se que para formar leitores precisamos como docentes, elaborar estratégias a serem tomadas para alcançarmos os objetivos com sucesso. Pois, a linguagem surge como instrumento mediador durante os movimentos interativos com as crianças e com seus colegas; no entanto, a linguagem oral não é a única maneira da criança se expressar; em seu universo, percebe-se o gesto, risos, expressões faciais, movimentos corporais que se constituem como as múltiplas linguagens dela. A atividade de contar história, da lugar à escuta da "voz da criança" e à interação criança-criança. As crianças sempre que interagem revelam as suas emoções, o entusiasmo pela história e demonstração de afeto entre si.

\section{CONCLUSÃO}

Neste artigo, enfatizamos a importância da contaçãode histórias na educação infantil e sua contribuição para os aspectos social, cognitivo para fortalecer as intenções educacionais e de aprendizagem das crianças. Ouvir e contar histórias é uma atividade que, entre outras coisas, pode cultivar as emoções das crianças, ajudá-las a se organizar e se socializar, além de ajudá-las no processo de alfabetização.

Desse modo, contar histórias é considerado uma ferramenta de ensino agradável e é muito útil para estabelecer o processo de aprendizagem de uma criança. Conclui-se que a pesquisa aqui apresentada é um recurso valioso na formação acadêmica, principalmente para os sujeitos envolvidos, por proporcionar a possibilidade de ampliar seus conhecimentos na área da educação infantil, bem como orientá-los a refletir sobre a prática vivenciada.

Portanto, percebemos que essa prática de contar histórias bem elaborada tem trazido uma contribuição significativa e fecunda para a construção de textos cada vez mais coerentes e imaginativos, e que a expressão oral promove um melhor desenvolvimento e torna mais fácil para as crianças Sinta a criatividade e supere a sua. barreiras de escrita. Também 
descobrimos que é cada vez mais conveniente para os professores inovar continuamente as salas de aula e buscar métodos de ensino em seu trabalho docente.

\section{REFERÊNCIAS}

AMARILHA, Marly. Estão mortas as fadas? Petrópolis, RJ: Vozes. Natal: EDUFRN, 1997.

CAVALCANTI, Joana. Caminhos da literatura infantil e juventude: dinâmicas e vivencias na ação pedagógica. São Paulo: Paulus, 2002.

FARIA, Maria Alice. Como usar a literatura infantil em sala de aula. São Paulo: Contexto, 2010.

JOLIBERT, Josette. Formando crianças leitoras. Vol. ı; Tradução Bruno C. Magne. Porto Alegre: Artes Médicas, 1994. SISTO, Celso. Textos e pretextos sobre a arte de contar histórias. Chapecó: Argos, 200I. 